05,12

\title{
Магнитные и резонансные свойства поликристалла $\mathrm{Y}_{0.5} \mathrm{Sr}_{0.5} \mathrm{Cr}_{0.5} \mathrm{Mn}_{0.5} \mathrm{O}_{3}$
}

\author{
(ㄷ Г.С. Патрин ${ }^{1,3}$, М.М. Матаев ${ }^{2}$, К.Ж. Сейтбекова ${ }^{2}$, Я.Г. Шиян ${ }^{1,3}$, С.А. Яриков ${ }^{1,3}$, С.М. Жарков ${ }^{1,3}$ \\ ${ }^{1}$ Сибирский феедеральный университет, \\ Красноярск, Россия \\ ${ }^{2}$ Казахский государственный женский педагогический университет, \\ Алма-Ата, Казахстан \\ ${ }^{3}$ Институт фризики им. Л.В. Киренского, ФИЦ КНЦ СО РАН, \\ Красноярск, Россия \\ E-mail: patrin@iph.krasn.ru
}

Поступила в Редакцию 15 апреля 2020 г.

В окончательной редакции 15 апреля 2020 г.

Принята к публикации 16 апреля 2020 г.

\begin{abstract}
Представлены результаты экспериментальных исследований магнитостатических и магниторезонансных свойств поликристаллической системы $\mathrm{Y}_{0.5} \mathrm{Sr}_{0.5} \mathrm{Cr}_{0.5} \mathrm{Mn}_{0.5} \mathrm{O}_{3}$. Получено, что преобладающим является внутрикристаллическое ферромагнитное взаимодействие, при этом межкристаллическое взаимодействие носит антиферромагнитный характер. Спектр магнитного резонанса в магнитоупорядоченной области состоит из двух линий. Высокополевая линия относится к взаимодействующим частям оболочек поликристаллитов, а низкополевой пик связан с неупорядоченной системой ферромагнитных частиц.
\end{abstract}

Ключевые слова: иттрий-стронциевый хромито-манганит, антиферромагнитное взаимодействие, обратная восприимчивость, магнитный резонанс.

DOI: 10.21883/FTT.2020.08.49602.089

\section{1. Введение}

В настоящее время активно изучаются соединения из класса материалов, относящихся к сложным оксидам. Практически, сложные оксиды привлекательны тем, что они являются химически инертными, стабильными. Создавая материалы на основе различных оксидов, удается получить как чисто магнитные соединения, так и те, которые относятся к классу мультиферроиков [1]. Большой интерес представляют неоднородные среды с развитыми границами раздела между мезоскопическими структурными элементами, каковыми являются системы с фазовым расслоением, пленочные структуры и наноразмерные композиты [2]. В этом направлении наиболее подробно исследованы соединения из класса манганитов с общей формулой $A_{x} B_{1-x} \mathrm{Mn}_{y} M e_{1-y} \mathrm{O}_{3}$, где $A$ - редкоземельный элемент, $B$ - как правило, щелочноземельный элемент, $M e-3 d$-метал [3]. Базовым соединением является $\mathrm{LaMnO}_{3}$. В частности, легирование этого соединения ионами $\mathrm{Sr}^{2+}$ в зависимости от концентрации примеси приводит к богатому разнообразию свойств и множественности переходов между различными магнитными фазами, в частности, при $x=0.5$ образец находится в антиферромагнитной фазе и имеет полупроводниковый тип проводимости [4]. В общем случае в таких системах магнитные и электрические свойства определяются соотношением ионов марганца $\mathrm{Mn}^{3+} / \mathrm{Mn}^{4+}$. С другой стороны, в смешанных хромитоманганитах возникают эффект обменного смещения изза конкуренции обменных взаимодействий между одно- и разноименными ионами $\mathrm{Cr}$ и $\mathrm{Mn}$ с разной валентностью $[5,6,7]$ и эффект версии знака намагниченности [8]. Ситуация еще больше усложняется при переходе на наноразмерный масштаб. В этом случае появляется дополнительный фактор (размер частиц) управления свойствами, например, в соединении $\mathrm{Y}_{0.95} \mathrm{Ca}_{0.05} \mathrm{MnO}_{3}$ обнаружено заметное изменение диэлектрической проницаемости от размеров наночастиц [9]. При внесении примесей иттрия вместо лантана наблюдаются аномальное изменение относительного объема, изменение обратной восприимчивости [10], а также релаксационные процессы намагниченности [11], характерные для спиновых стекол. Вышеизложенное демонстрирует заметное влияние ионов иттрия на магнитные свойства кристаллов манганитов. В поликристаллическом лантанстронциевом манганите, легированном хромом в малых концентрациях $(<8 \%)$, наблюдается возвратное спинстекольное поведение [12]. При этом сильное влияние на набор свойств поликристаллов оказывает технология получения образцов. При переходе на наноразмерный масштаб возникает как пространственная неоднородность внутри частиц, так и добавляются межчастичные взаимодействия.

В литературе практически отсутствуют данные по свойствам манганитов на основе иттрия, а внедрение ионов хрома вместо ионов марганца расширяет многообразие возможных обменных взаимодействий. Поэтому мы решили исследовать магнитные свойства поликристаллических иттрий-стронциевых хромито-манганитов. 


\section{2. Экспериментальная часть}

Для получения манганта $\mathrm{Y}_{0.5} \mathrm{Sr}_{0.5} \mathrm{Cr}_{0.5} \mathrm{Mn}_{0.5} \mathrm{O}_{3}$ использовалась смесь окислов $\mathrm{Y}_{2} \mathrm{O}_{3}, \mathrm{SrCO}_{3}, \mathrm{Cr}_{2} \mathrm{O}_{3}, \mathrm{Mn}_{2} \mathrm{O}_{3}$. Полученные образцы сложных оксидов были приготовлены методом золь-геля [13]. Стехиометрические количества оксидов смешивали и растирали в агатовой ступке до получения гомогенной смеси. Затем смеси подвергали повторному отжигу в печи в интервале температур $600-1100^{\circ} \mathrm{C}$ с повышением температуры на каждые $100^{\circ} \mathrm{C}$. С целью улучшения гомогенности продуктов реакции отжиг проводился в 6 этапов: I этап $-600^{\circ} \mathrm{C}$, II - этап $700^{\circ} \mathrm{C}$, III - этап $800^{\circ} \mathrm{C}$, IV — этап $900^{\circ} \mathrm{C}$, $\mathrm{V}$ - этап $1000^{\circ} \mathrm{C}, \mathrm{VI}$ - этап $1100^{\circ} \mathrm{C}$ с общей продолжительностью 39 часов. Промежуточное измельчение производилось после каждой стадии синтеза. По завершении синтеза печь выключали, и охлаждение полученного соединения осуществлялось в режиме охлаждения муфельной печи.

Фазовое состояние конечных продуктов контролировалось методом рентгенофазового анализа, который проводили на рентгеновском дифрактометре Miniflex 600 (Rigaku). Электронно-микроскопические измерения проводились на микроскопе JEOL JEM-2100. Магнитные характеристики изучались на СКВИД-магнитометре MPMS-XL в полях до $50 \mathrm{kOe}$ Спектры электронного магнитного резонанса (ЭМР) измерялись на спектрометре Bruker E $500 \mathrm{CW}$ EPR, действующем на частоте $\omega_{\mathrm{MWF}}=9.48 \mathrm{GHz}$. Резонансные измерения проводились в интервале температур 5-300 K.

\section{3. Результаты и обсуждение}

Методом рентгеновской спектроскопии было установлено, что кристаллы соответствуют номинальному составу и принадлежат орторомбической сингонии с пара-

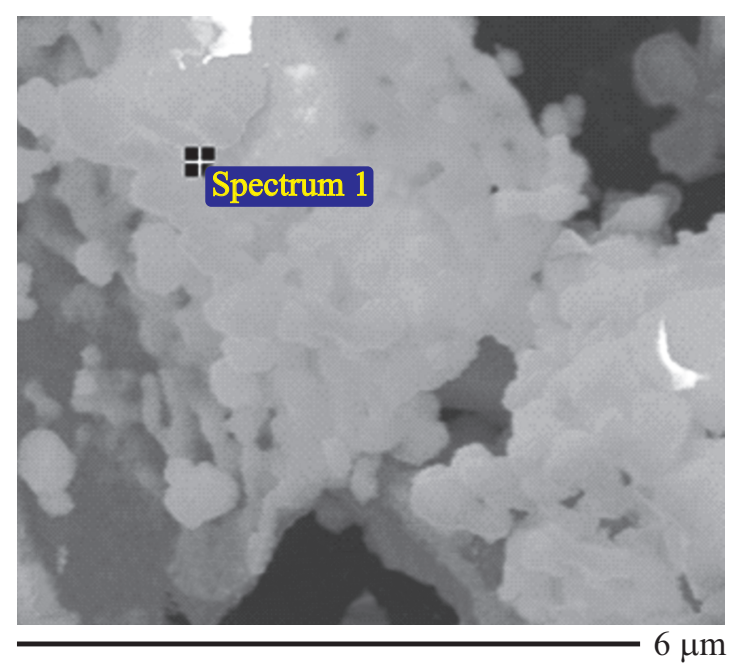

Рис. 1. Электронно-микроскопическое избражение поликристалла хромито-манганита состава $\mathrm{Y}_{0.5} \mathrm{Sr}_{0.5} \mathrm{Cr}_{0.5} \mathrm{Mn}_{0.5} \mathrm{O}_{3}$.

\begin{tabular}{c|c|c}
\hline Элемент & $\begin{array}{c}\text { Весовое } \\
\text { содержание, \% }\end{array}$ & $\begin{array}{c}\text { Атомное } \\
\text { содержание, \% }\end{array}$ \\
\hline $\mathrm{O}$ & 22.3 & 60.1 \\
$\mathrm{Cr}$ & 13.7 & 9.6 \\
$\mathrm{Mn}$ & 15.53 & 10.3 \\
$\mathrm{Sr}$ & 24.53 & 10.2 \\
$\mathrm{Y}$ & 23.94 & 9.8 \\
& 100.00 & 100.00
\end{tabular}

метрами ячейки $a=7.065 \AA, b=7.375 \AA, c=6.741 \AA$. O среднем размере кристаллитов, можно судить по электронно-микроскопическому избражению на рис. 1 (виден значительный разброс по размерм кристаллитов). В таблице приведены локальные значения содержания химических элементов, полученные методом просвечивающей спектроскопии, как в атомном содержании, так и в весовом. Диаметр пятна (отмечено на рис. 1), с которого снималась информация, составляет $\sim 20 \mathrm{~nm}$. Разброс содержания элементов в образце от точки к точке может составлять 5-6\%.

Как правило [3], манганиты различного состава кристаллизуются в орторомбической симметрии. В ряде случаев в следствие искажения октаэдра $\mathrm{MnO}_{6}$ нанофазные манганитные системы (например, $\mathrm{La}_{1-x} \mathrm{Me}_{x} \mathrm{MnO}_{3}$, $M e=\mathrm{Ca}, \mathrm{Sr}[14,15])$ имеют переход в моноклинную симметрию. Однако есть данные [7], что поликристаллы $\mathrm{La}_{0.5} \mathrm{Sr}_{0.5} \mathrm{Mn}_{0.5} \mathrm{Cr}_{0.5} \mathrm{O}_{3}$, полученные стандартным методом твердофазной реакции на воздухе представляют собой смесь ромбоэдрической $(42 \%)$ и орторомбической $(51 \%)$ фаз. В магнитном отношении образцы в целом показывают антиферромагнитное поведение.

В результате магнитостатических измерений установлено, что при низких температурах наблюдаются гистерезисные петли намагничивания. Ниже 30 К петля гистерезиса является раскрытой (рис. 2), но насыщение намагниченности не достигается вплоть до полей $H \geq 50 \mathrm{kOe}$. При температурах $T>35 \mathrm{~K}$ кривая намагничивания является безгистерезисной и имеет вид, типичный для парамагнетика, с наклоном прямой существенно зависящей от температуры измерения (вставка на рис. 2). Вид температурных кривых намагниченности, полученных при отогреве образца $(M(T))$, зависит от предыстории: или режим охлаждения: в магнитном поле (FC), или охлаждение в нулевом магнитном поле (ZFC). Как раз при температуре $T \approx 35 \mathrm{~K}$ в режиме $\mathrm{ZFC}$ в малых магнитных полях имеет место максимум в зависимости $M(T)$. В полях около $2.5 \mathrm{kOe}$ появляется низкотемпературный „хвост“ намагниченности, удельный вес которого растет с повышением поля измерения. В более высоких полях измерения происходит сглаживание максимума и в полях $H>40 \mathrm{kOe}$ он практические не проявляется (рис. 3). На рис. 4 приведены температурные зависимости обратной восприимчивости $(1 / \chi)$, полученные в разных магнитных полях (для стан- 


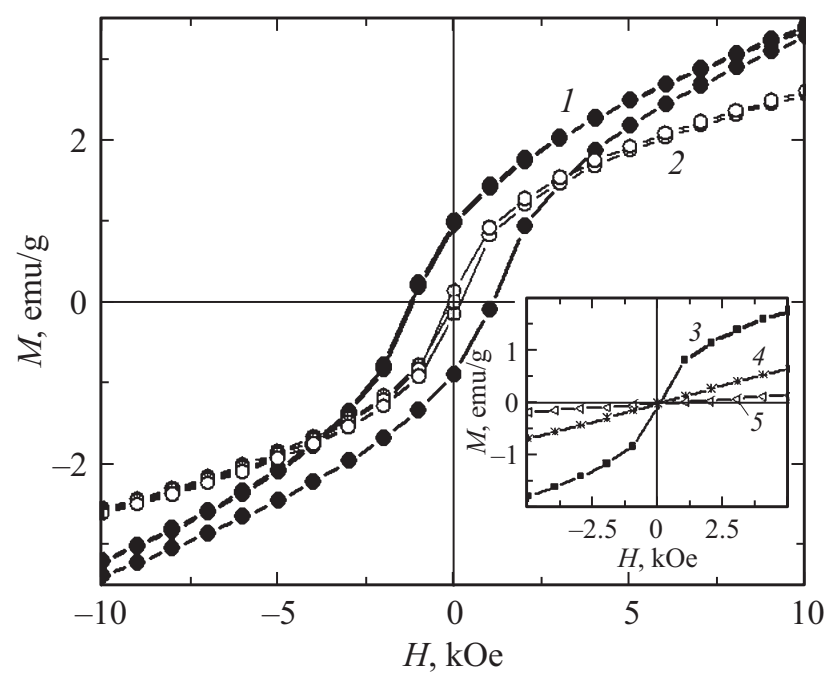

Рис. 2. Полевые зависимости намагниченности поликристалла $\mathrm{Y}_{0.5} \mathrm{Sr}_{0.5} \mathrm{Cr}_{0.5} \mathrm{Mn}_{0.5} \mathrm{O}_{3}$. Кривые $1,2,3,4,5$ для $T=4.5,25,35,75$, $170 \mathrm{~K}$ соответственно.

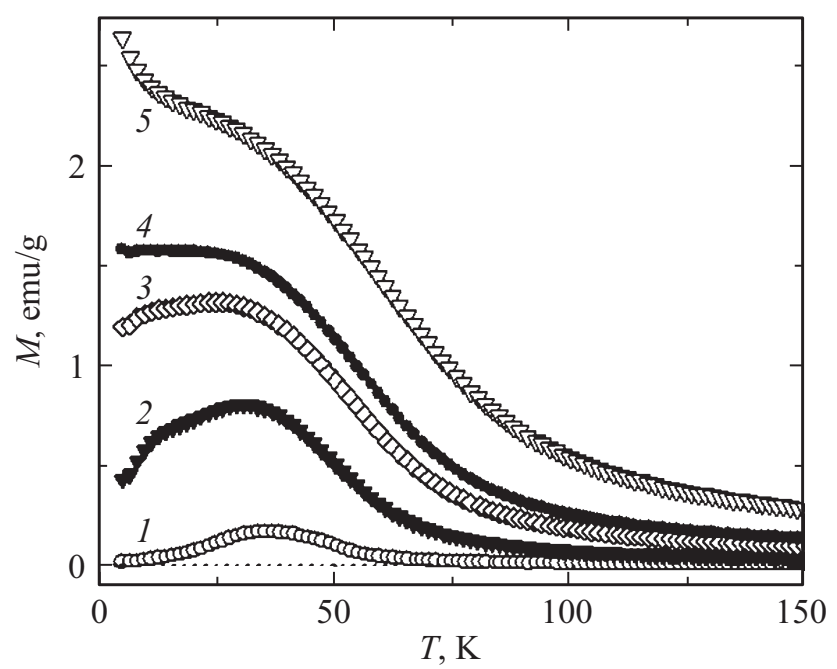

Рис. 3. Температурные зависимости намагниченности поликристалла $\mathrm{Y}_{0.5} \mathrm{Sr}_{0.5} \mathrm{Cr}_{0.5} \mathrm{Mn}_{0.5} \mathrm{O}_{3}$. Кривые $1,2,3,4,5$ для $H=0.15,1.0,2.5,3.5,7.5 \mathrm{kOe}$ соответственно.

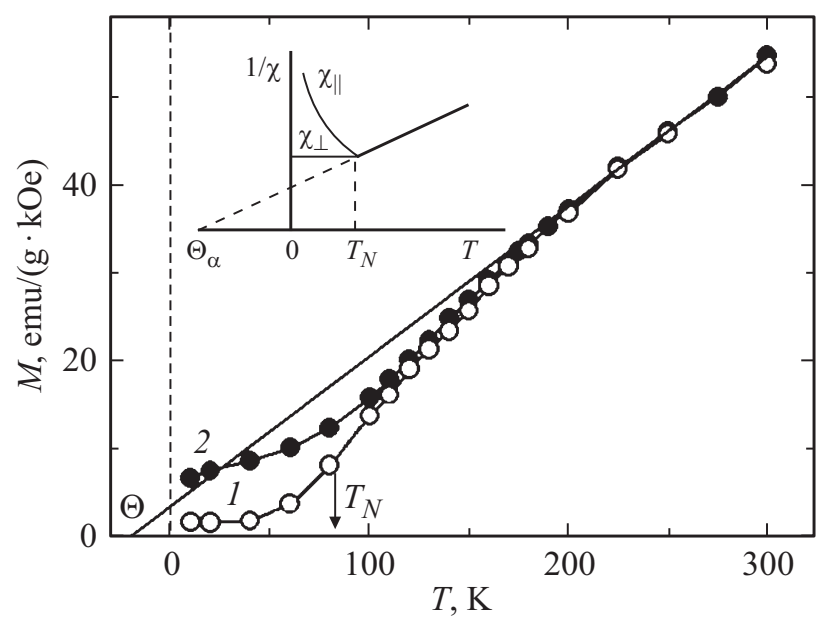

Рис. 4. Температурные зависимости обратной восприимчивости. $1-2.5 \mathrm{kOe}, 2-40 \mathrm{kOe}$. На вставке модельная зависимость для $1 / \chi(T)$ взято из работы [13].
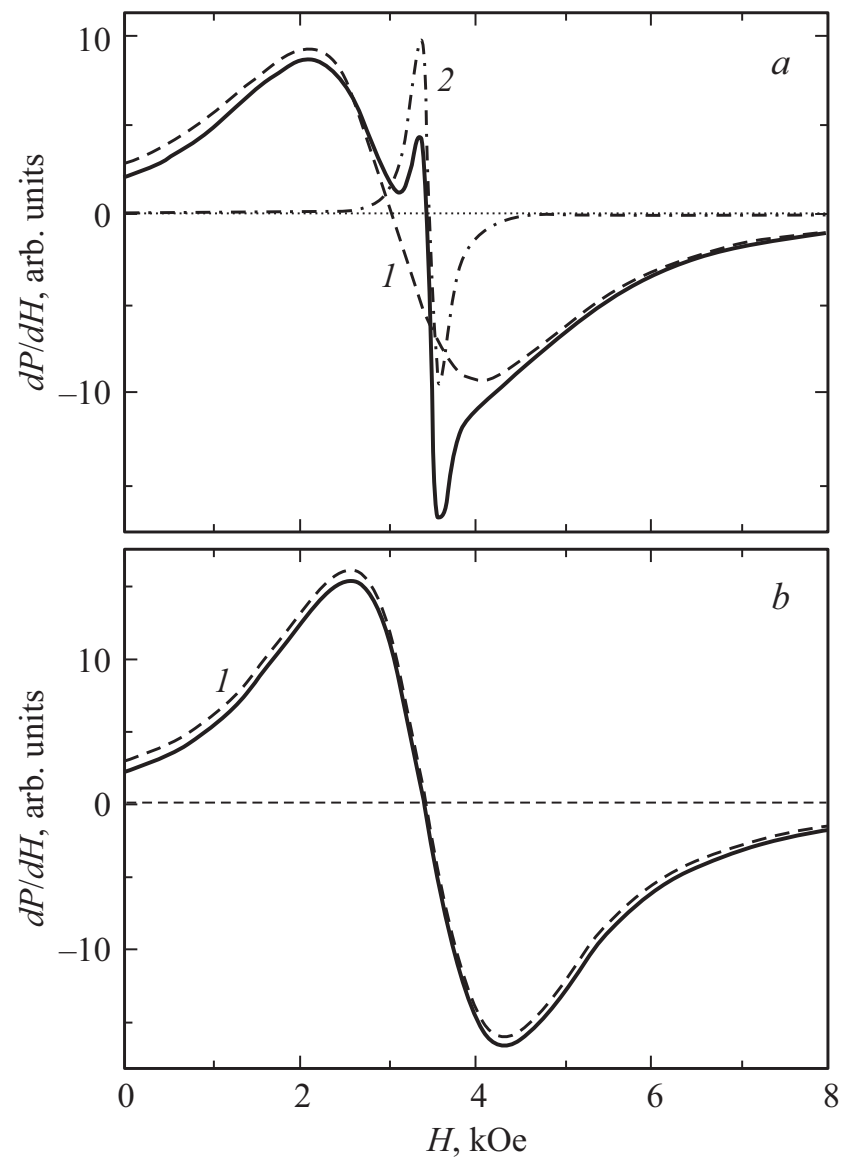

Рис. 5. Спектр резонансного поглощения в поликристалле $\mathrm{Y}_{0.5} \mathrm{Sr}_{0.5} \mathrm{Cr}_{0.5} \mathrm{Mn}_{0.5} \mathrm{O}_{3} .(a)-T=39.5 \mathrm{~K},(b)-T=270 \mathrm{~K}$. 1,2 - подгонка лоренцевскими кривыми, 3 - экспериментальная кривая.

дартного двух подрешеточного антиферромагнетика [16] $\chi=C /(T-\Theta)$, где $C-$ константа, $T-$ температура, $\Theta-$ точка пересечения асимптоты с осью абсцисс, зависящая от соотношения внутри- и межподрешеточного обменов). Там же на вставке показано качественное поведение $1 / \chi$ для антиферромагнетика для разных направлений магнитного поля относительно оси антиферромагнетизма. Видно, что экспериментальная зависимость $1 / \chi(T)$ качественно соответствует антиферромагнитному упорядочению для поликристалла [16]. Для поля измерения $H=2.5 \mathrm{kOe}$ загиб на кривой $1 / \chi(T)$ начинает отчетливо проявляться в районе $T_{N} \approx 75-90 \mathrm{~K}$, что можно связать с температурой Нееля. Для всех полей измерения величина $\Theta=-27 \mathrm{~K}$, тогда как температура $T_{N}$ зависит от поля измерения.

На рис. 5 приведены спектры СВЧ поглощения поликристаллического образца при $T=39 \mathrm{~K}$ и $T=270 \mathrm{~K}$. При температурах $T<80 \mathrm{~K}$ спектр состоит из двух линий резонансного поглощения (часть $a$ ), а в области высоких температурах наблюдается одна линия (часть $b$ ), низкополевая (линия 1). При повышении температуры высокополевая линия существенно умень- 
шаясь по интенсивности, исчезает в районе $T \sim 80 \mathrm{~K}$, что приблизительно совпадает с районом $T_{N}$.

Качественно полученные результаты можно понять в рамках модели двухподрешеточного антиферромагнетика. Если $J_{1}>0$ и $J_{2}<0$ внутри- и межподрешеточные обменные взаимодействия, то согласно [13], $\Theta=J_{1}+J_{2}$, a $T_{N}=J_{1}-J_{2}$. Используя экспериментальные значения $\Theta$ и $T_{N}$, в данном случае получаем $J_{1} \approx+29 \mathrm{~K}$ и $J_{2} \approx-56 \mathrm{~K}$.

В настоящее время в литературе практически отсутствуют данные по исследованию смешанных иттриевых хромито-манганитов, а имеющиеся данные относятся к соединениям с лантаном $[7,12,17,18]$. В лантан-стронциевых манганитах, в соответствие с фазовой диаграммой [19] концентрация $x=0.5$ является пограничной между ферромагнитной фазой и антиферромагитной. Поэтому внедрение ионов хрома и переход на мезоскопический уровень кристаллитов может сдвигать границу фазового перехода ферромагнетик-антиферромагнетик в ту или иную сторону.

Для монокристаллических манганитов, как правило, межподрешеточное взаимодействие заметно больше внутри подрешеточного взаимодействия [3]. В нашем случае средний размер кристаллитов имеет достаточно большое значение $(\approx 10.3 \mathrm{mkm})$. Здесь наряду с магнитным порядком внутри кристаллитов, присутствует межкристаллическое обменное взаимодействие, которое может иметь сравнимую величину с обменом внутри кристаллитов, и тогда возникает конкуренция взаимодействий. Наличие низкотемпературного хвоста намагниченности в больших магнитных полях свидетельствует о наличие суперпарамагнитной подсистемы, а, как показано в [12], поведение в слабых магнитных полях для $\mathrm{La}-\mathrm{Sr}-\mathrm{Mn}-\mathrm{Cr}$ системы (с малым содержанием $\mathrm{Cr}$ ) подобно спин-стекольному. Это дает основание считать, что гранулы являются ферромагнитными, случайным образом ориентированные в пространстве, а между гранулами имеет место антиферромагнитное взаимодействие. При этом межкристаллические обменные взаимодействия должны быть меныше внутрикристаллического. Ясно, что в такой системе имеет место конкуренция межкристаллических взаимодействий. Тогда намагничивание в малых магнитных полях $H \leq H_{E X}$, (где $H_{E X}-$ обменное поле межкристаллического взаимодействия) определяется поворотом магнитных моментов ферромагнитных кристаллитов, и здесь поведение намагниченности подобно спин-стекольному (рис. 3, кривые 1,2). Поведение в более высоких магнитных полях $\left(H>H_{E X}\right)$ определяется преодолением межкристаллических антиферромагнитных взаимодействий и разворотом магнитных моментов кристаллитов вдоль направления внешнего магнитного поля (рис. 3, кривые 3, 4). В сильных магнитных полях намагничивание связано с преодолением самых сильных межчастичных взаимодействий и внутри частичных магнитных анизотропий (рис. 3, кривая 5).

Как известно [20], манганиты в наночастичном и поликристаллическом состояниях имеют сильную простран- ственную неоднородность, когда ядро частицы окружено поверхностной оболочкой, которая, как правило, имеет другой состав и даже может иметь другую структуру. Тогда ансамбль взаимодействующих частиц можно представить как двухфазную магнитную систему: внутренний объем и оболочка. Данные магнитного резонанса показывают, что при низких температурах мы видим две моды колебаний (рис. 5,a), это указывает на существование двух подсистем. При этом низкополевой резонансный пик имеет интенсивность (определяемую как площадь под соответствующей кривой) примерно на порядок большую, чем высокополевой пик и значительно большую ширину линии. Приблизительно резонансные поля приходятся на область $2-3 \mathrm{kOe}$, что соответствует области сглаживания максимума на рис. 3 и переходу в область преодоления антиферромагнитных межкристаллических взаимодействий. Выше температуры перехода $\left(T_{N}\right)$ высокополевой пик исчезает на фоне низкополевого (рис. 5,b), а параметры низкополевого пика практически не зависят от температуры. Эти данные дают основание считать, что высокополевой пик происходит от той части образца, которая связана с оболочкой поликристаллов и, когда исчезает дальний порядок, эта часть не видна на фоне низкополевого пика. Низкочастотное поглощение, таким образом, связано с резонансом от неупорядоченной системы ферромагнитных кластеров (кристаллитов). Об этом свидетельствует и уширение наблюдаемой линии резонансного поглощения. Однако получение более детальной информации о резонансных свойствах требует дополнительных специальных исследований.

\section{Финансирование работы}

Измерение спектров магнитного резонанса проводились на оборудовании ЦКП ФИЦ КНЦ СО РАН.

Настоящие исследования ведутся при финансовой поддержке Министерства образования и науки Республики Казахстан (грант № 05130165) и в рамках договора о сотрудничестве между Сибирским федеральным университетом и Казахским государственным женским педагогическим университетом.

\section{Конфликт интересов}

Авторы заявляют, что у них нет конфликта интересов.

\section{Список литературы}

[1] N.A. Spaldin, S.-W. Cheong, R. Ramesh. Phys. Today 63, 38 (2010).

[2] Why Nanoscale Ferroelectrics and Multiferroics? In book: Nanoscale Ferroelectrics and Multiferroics. V. 1. / Eds M. Alguero, J.M. Gregg, L. Mitoseriu. John Wiley \& Sons Ltd, United Kingdom (2016). P. 26.

[3] E. Dagotto. Nanoscale phase separation and colossal magnetoresistance. The physics of manganites and related compounds. Ch. 13. Springer. Berlin (2003), 273 p. 
[4] C. Moure, O. Pena. JMMM 337-338, 1 (2013).

[5] T. Bora, S. Ravi. J. Appl. Phys. 114, 183902 (5) (2013).

[6] C.L. Li, S. Huang, X.X. Li, C.M. Zhu, G. Zerihun, C.Y. Yin, C.L. Lu, S.L. Yuan. JMMM 432, 77 (2017).

[7] N. Kallel, M. Hazzez, N. Ihzaz. J. Supercond. Nov. Magn. 32, 2623 (2019).

[8] A. Kumar, S.M. Yusuf . Phys. Rep. 556, 1 (2015).

[9] N.A. Shah. Appl.Nanosci. 4, 889 (2014).

[10] M.R. Ibarra, P.A. Algarabel, C. Marquina, J. Blasco, J. García. Phys. Rev. Lett. 75, 3541 (1995).

[11] R.S. Freitas, L. Ghivelder, F. Damay, F. Dias, L.F. Cohen. Phys. Rev. B 64, 144404 (2001).

[12] J. Dho, W.S. Kim, N.H. Hur. Phys. Rev. Lett. 89, (4), 027202 (2002).

[13] M.M. Mataev, G.S. Patrin, K.Zh. Seitbekova, Zh.Y. Tursinova, M.R. Abdraimova. Orient. J. Chem. 35, 1162 (2019).

[14] K.S. Shankar, S. Kar, G.N. Subbanna, A.K. Raychaudhuri. Solid State Commun. 129, 479 (2004).

[15] J. Dho, S. Ki. J. Phys. Chem. Solids 75, 1372 (2014).

[16] С. Тикадзуми. Физика ферромагнетизма. Магнитные свойства вещества. Мир, М. (1983). Ч. 1. С. 160.

[17] O. Cabeza, M. Long, C. Severac, M.A. Bari, C.M. Muirhead, M.G. Francesconi, C. Greaves. J. Phys.: Condens. Matter. 11, 2569 (1999).

[18] C.S. Honga, N.H. Hurb, Y.N. Choi. Solid State Commun. 133, 531 (2005).

[19] A. Urushibara, Y. Moritomo, T. Arima, A. Asamitsu, G. Kido, Y. Tokura. Phys. Rev. B 51, 14103 (1995).

[20] V. Markovich, A. Wisniewski, H. Szymczak. Magnetic Properties of Perovskite Manganites and Their Modifications. In book: Handbook of Magnetic Materials. V. 22 / Ed. K.H.J. Bushow. Elsevier B.V. (2014). P. 1.

Редактор К.В. Емцев 